Proceedings

\title{
Gas Sensing Properties of Carbon Nanotubes Decorated with Iridium Oxide Nanoparticles ${ }^{\dagger}$
}

\author{
Juan Casanova-Cháfer, Èric Navarrete and Eduard Llobet * \\ MINOS-EMaS, Universitat Rovira i Virgili, 43007 Tarragona, Spain; juan.casanova@urv.cat (J.C.-C.); \\ eric.navarrete@urv.cat (È.N.) \\ * Correspondence: eduard.llobet@urv.cat; Tel.: +34-997-558-502 \\ † Presented at the Eurosensors 2018 Conference, Graz, Austria, 9-12 September 2018. \\ Published: 30 November 2018
}

\begin{abstract}
The properties of Iridium oxide $\left(\mathrm{IrO}_{2}\right)$ decorated Multi-Wall Carbon Nanotubes $\left(\mathrm{IrO}_{2}-\right.$ MWCNTs) are studied for detecting nitrogen dioxide and ammonia vapors. $\mathrm{IrO}_{2}$ nanoparticles were synthetized using a hydrolysis and acid condensation growth mechanism, and subsequently employed for decorating the sidewalls of carbon nanotubes. Decorated MWCNTs films were deposited onto $\mathrm{SiO}_{2} / \mathrm{Si}$ substrates for achieving chemoresistive gas sensors. $\mathrm{NO}_{2}$ and $\mathrm{NH}_{3}$ gases were detected under different experimental conditions. Higher and more stable responses towards $\mathrm{NH}_{3}$ and $\mathrm{NO}_{2}$ were observed for iridium-oxide nanoparticle decorated MWCNT material, compared to bare MWCNT material. Raman Spectroscopy was employed to study the nanomaterials and the optimal operating temperatures were determined.
\end{abstract}

Keywords: carbon nanotubes; iridium oxide; metal nanoparticles; gas sensing

\section{Introduction}

Carbon nanotubes have been widely used in gas sensing applications due to their suitable electronic, physical and chemical properties, such as high surface area to volume ratio, nanometersized and high carrier mobility. However, some sensing properties (e.g., sensitivity, selectivity and reproducibility) can be enhanced by the functionalization of their external sidewalls. Different options are well-known, such as grafting functional groups onto the carbon nanotubes surface or decorating them with metal or metal oxide nanoparticles. Here we explore the improvements obtained by loading MWCNTS with $\mathrm{IrO}_{2}$ nanoparticles. While the use of $\mathrm{IrO}_{2}$ has been reported for electrochemical sensing and catalyst for water splitting [1], little information is available on its use for chemoresistive gas sensing.

\section{Materials and Methods}

\subsection{Material Synthesis}

Iridium oxide $\left(\mathrm{IrO}_{2}\right)$ nanoparticles were synthetized using the method proposed by Zhao [2], in which we prepare a solution of iridium oxide nanoparticles via two-step process (Figure 1). The first step consists in the hydrolysis of $\mathrm{K}_{2} \mathrm{IrCl}_{6}$, breaking the $\mathrm{Ir}-\mathrm{Cl}$ bonds and creating the complex $\left[\operatorname{Ir}(\mathrm{OH})_{6}\right]^{-2}$ at $\mathrm{pH} 13$ using $\mathrm{NaOH}$. Moving from yellow $\left(\mathrm{K}_{2} \mathrm{IrCl}_{6}\right)$ to light blue $\left(\left[\operatorname{Ir}(\mathrm{OH})_{6}\right]^{-2}\right)$ dissolution. The second step is the acid condensation process, in which we use $\mathrm{HNO}_{3} 3 \mathrm{M}$ to decrease the $\mathrm{pH}$ to 1 under vigorous stirring. In this step we achieve the protonation and condensation of $\left(\left[\operatorname{Ir}(\mathrm{OH})_{6}\right]^{-2}\right)$ to form $\mathrm{IrO}_{2}$ nanoparticles, changing from light blue to deep blue color. An important consideration is that the dissolution should be stored at $2{ }^{\circ} \mathrm{C}$ in order to avoid the formation of precipitates. 


\section{$\left[\mathrm{IrCl}_{6}\right]^{-2} \stackrel{\mathrm{OH}^{-}}{\longrightarrow}-\left[\mathrm{Ir}(\mathrm{OH})_{6}\right]^{-2} \stackrel{\mathrm{H}^{+}}{\longrightarrow}-\mathrm{IrO}_{2}+\mathrm{nH}_{2} \mathrm{O}$}

Figure 1. Mechanism to synthetize iridium oxide nanoparticles.

\subsection{Material Characterization}

Raman spectroscopy was employed to evaluate the carbon nanotubes crystallinity. The spectra show the well-known bands at $1350 \mathrm{~cm}^{-1}$ (D), $1580 \mathrm{~cm}^{-1}$ (G), $2680 \mathrm{~cm}^{-1}$ (2D) and $2950 \mathrm{~cm}^{-1}$ (2iTO). Comparing the intensity ratio D/G bands, we can conclude that our MWCNTs present a low level of crystallinity. However, the presence of these defects play an essential role in the anchoring process of $\mathrm{IrO}_{2}$ nanoparticles.

In addition, Raman measurements revealed the MWCNTs decoration with $\mathrm{IrO}_{2}$ (Figure 2), and the $\mathrm{IrO}_{2}$ active modes (Eg, $\mathrm{B}_{2 \mathrm{~g}}$ and $\mathrm{A}_{1 \mathrm{~g}}$ ) previously reported in other works [3].

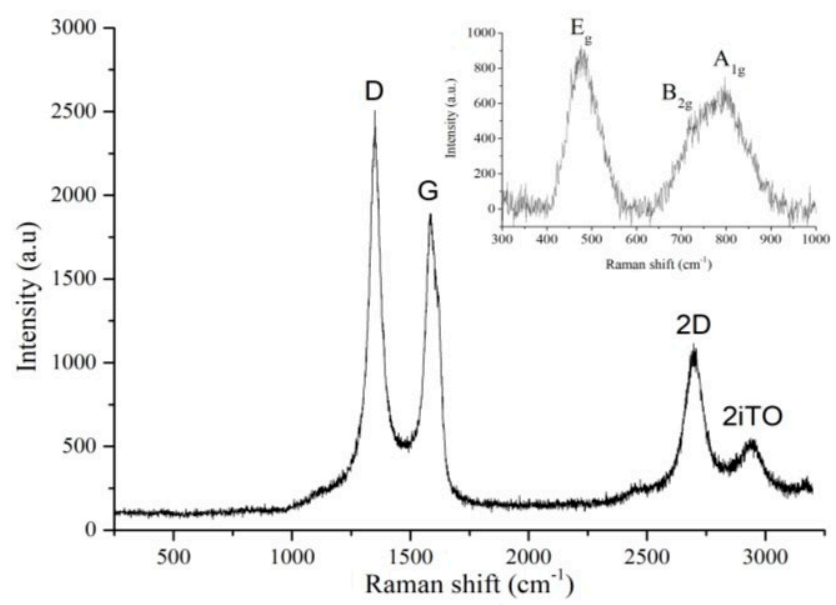

Figure 2. Raman spectra of MWCNTs with a zoom in the $300-1000 \mathrm{~cm}^{-1}$ region (in the inset) corresponding to iridium oxide nanoparticles.

\subsection{Sensor Design}

Decorated MWCNTs were deposited through airbrush technique on oxidized piece of silicon wafer. Then, a platinum screen-printed alumina heater was connected in the backside of silicon wafer and was bonded to a printed circuit board (PCB). Finally, two wire contacts were made on the surface employing a silver paste (Ag component metallization, Heraeus). The sensor design was adapted to be placed in a Teflon test chamber which is connected to a gas mixture system.

\subsection{Gas Sensing Methodology}

The concentrations analyzed for both, nitrogen dioxide and ammonia gases, were done at three different operating temperatures. The total flow was adjusted to $100 \mathrm{~mL} / \mathrm{min}$ using calibrated gas cylinders and mass-flow controllers. The sensors were stabilized with synthetic dry air (Air Premier Purity: 99.995\%) during $1 \mathrm{~h}$ between the target gas concentration exposures (30 min), and successive dilutions were done to apply the desired concentrations.

\section{Results}

$\mathrm{NH}_{3}$ and $\mathrm{NO}_{2}$ gas sensing measurements were performed at ppm and ppb levels, respectively, showing a suitable, improved sensitivity, stability and reproducibility of the response (see Figure 3) for iridium oxide doped MWCNTs. In case of $\mathrm{NH}_{3}$ detection, a significant increase in response (6fold) for doped MWCNTs was observed. Moreover, a higher response, better reproducibility and higher stability of $\mathrm{IrO}_{2}-\mathrm{MWCNT}$ can be observed. In addition, different temperatures were tested, 
and while $\mathrm{IrO}_{2}$-MWCNTs presented higher response than bare MWCNTs for all the temperatures studied, the best operating temperature was found to be $100{ }^{\circ} \mathrm{C}$. (Figure $4 \mathrm{a}$ )

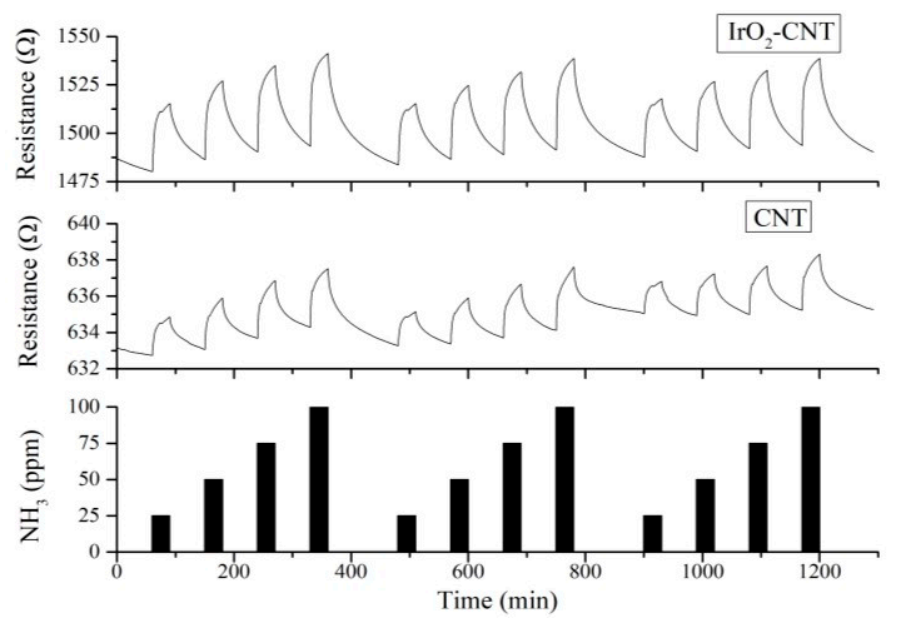

Figure 3. Example of the resistance response obtained for $\mathrm{NH}_{3}$ detection at $100{ }^{\circ} \mathrm{C}$.

Moreover, it can be observed that a better responsiveness towards ppb levels or $\mathrm{NO}_{2}$ (2-fold increase) was obtained for $\mathrm{IrO}_{2}$-MWCNTs. The optimal $\mathrm{NO}_{2}$ detection temperature was $150{ }^{\circ} \mathrm{C}$ (see Figure $4 \mathrm{~b}$ ) and the inset indicates that the highest response was observed at this temperature. Some aromatic volatile organic compounds (VOCs), such as benzene and toluene were measured at low concentrations and different operating temperatures. However, no response was obtained during the exposure to these target gases.
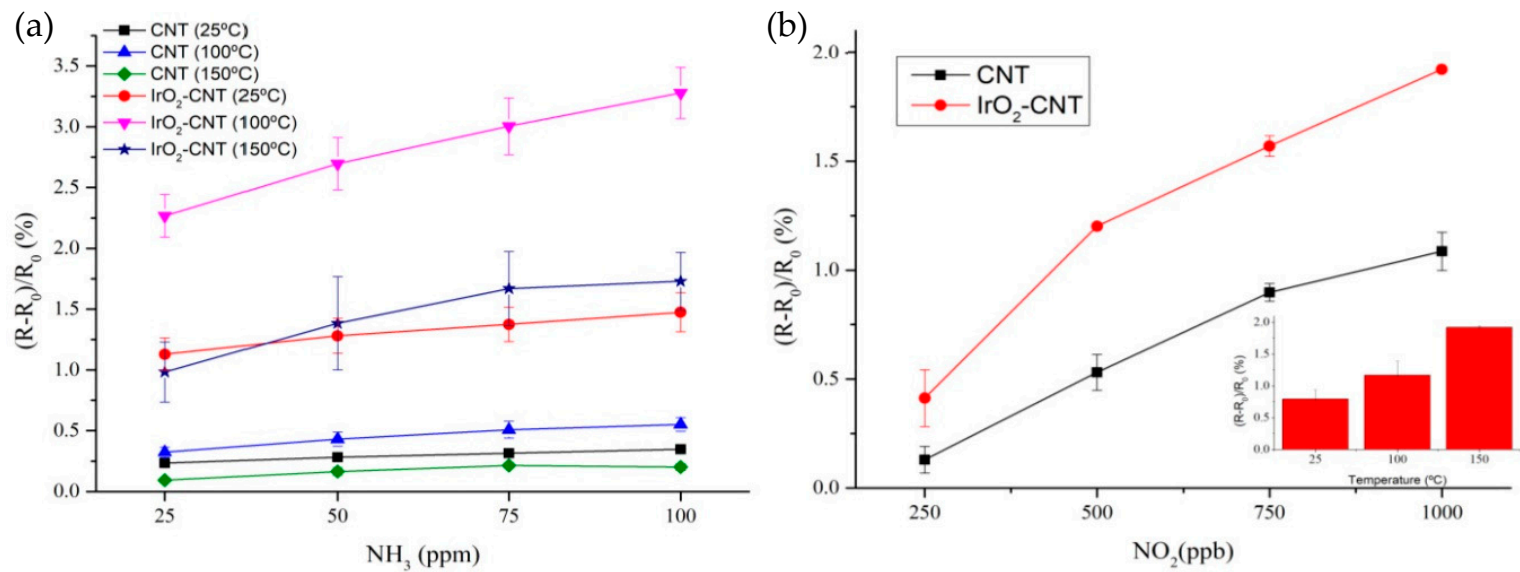

Figure 4. (a) Response obtained for $\mathrm{NH}_{3}$ at different temperatures; (b) $\mathrm{NO}_{2}$ gas sensing results.

In addition, the humidity effect on gas sensing was studied, showing an important increasing in the response (4-fold) for bare carbon nanotubes, probably because of transfer electron from water molecules depletes the concentration of holes [4]. However, the sensitivity of decorated MWCNTs remains similar with and without the presence of ambient moisture. $50 \%$ of relative humidity was tested on sensors operated at room temperature and $100{ }^{\circ} \mathrm{C}$ for detecting $\mathrm{NH}_{3}$, and the response of iridium oxide decorated carbon nanotubes shows that this nanomaterial show responses that are quite independent of humidity conditions

\section{Conclusions}

In this work, we develop a p-type sensor based on decorated MWCNTs with $\mathrm{IrO}_{2}$ nanoparticles on their sidewalls. This semiconductor nanomaterial shows an enhanced sensitivity to toxic gases such as nitrogen dioxide and ammonia. In addition, in contrast to bare nanotubes, $\mathrm{IrO}_{2}-\mathrm{MWCNTs}$ 
show a gas sensing mechanism rather independent of the relative humidity level. Besides, decorated carbon nanotubes present some selectivity against aromatic VOCs.

Author Contributions: J.C.-C. synthesized the nanoparticles, performed the experiments and contributed to the discussion and the writing. Ė.N. assisted to the synthesis. E.L. supervised the work and contributed to the discussion of results.

Funding: This research was funded by Martí i Franquès pre-doctoral fellowship from Universitat Rovira i Virgili (URV); MINECO under grant No. TEC2015-71663-R and E.L. by Catalan Institution for Research and Advanced Studies via the ICREA Academia Award.

Acknowledgments: We are thankful to Mrs. Moncusí for the help in Raman experiments.

Conflicts of Interest: The authors declare no conflict of interest.

\section{References}

1. Blakemore, J.D.; Crabtree, R.H.; Brudvig, G.W. Molecular Catalysts for Water Oxidation. Chem. Rev. 2015, $115,12974-13005$.

2. Zhao, Y.; Hernandez-Pagan, E.A.; Vargas-Barbosa, N.M.; Dysart, J.L.; Mallouk, T.E. A high yield synthesis of ligand-free iridium oxide nanoparticles with high electrocatalytic activity. J. Phys. Chem. Lett. 2011, 2, 402-406.

3. Korotcov, A.V; Huang, Y.-S.; Tiong, K.-K; Tsai, D.-S. Raman scattering characterization of well-aligned $\mathrm{RuO}_{2}$ and $\mathrm{IrO}_{2}$ nanocrystals. J. Raman Spectrosc. 2007, 38, 1538-1553.

4. Liu, L.; Ye, X.; Wu, K.; Han, R.; Zhou, Z.; Cui, T. Humidity Sensitivity of Multi-Walled Carbon Nanotube Networks Deposited by Dielectrophoresis. Sensors 2009, 9, 1714-1721.

() 2018 by the authors. Licensee MDPI, Basel, Switzerland. This article is an open access article distributed under the terms and conditions of the Creative Commons Attribution (CC BY) license (http://creativecommons.org/licenses/by/4.0/). 